\title{
Macroinvertebrate response to different species of macroalgal mats and the role of disturbance history
}

\author{
P.G. Cardoso ${ }^{\text {a,* }}$, M.A. Pardal ${ }^{\text {a }}$, D. Raffaelli ${ }^{\text {b }}$, \\ A. Baeta ${ }^{a}$, J.C. Marques ${ }^{\mathrm{a}}$ \\ a Department of Zoology, IMAR-Institute of Marine Research, University of Coimbra, \\ 3004-517 Coimbra, Portugal \\ ${ }^{\mathrm{b}}$ Environment Department, University of York, Heslington, York YO10 5DD, UK
}

Received 22 July 2003; received in revised form 24 February 2004; accepted 26 February 2004

\begin{abstract}
Over the last 20 years, the Mondego estuary, Portugal has experienced excessive growth of macroalgae especially in the inner parts of the system, with several algal species implicated. In this study, we compare the effects of morphologically different species, the red alga Gracilaria verrucosa and the green macroalga Enteromorpha intestinalis on macrobenthic assemblages, by a field experiment whereby the biomass of algae was manipulated and the resultant changes in macrofauna abundance evaluated. The experiments were carried out in different areas (a relatively undisturbed sea grass bed and an upstream eutrophic area) experiencing different degrees of overall enrichment.

Measurements of sediment redox potential revealed a rapid anoxia with a significant increase in algal biomass after 4 weeks. The effects of macroalgae were different at the two sites, being more marked in the eutrophic area. In addition, the effects of Gracilaria and Enteromorpha were significantly different, with Enteromorpha having a greater detrimental effect for most of the macrofauna, in particular Cyathura carinata, Scrobicularia plana, Cerastoderma edule and Alkmaria romijni. However, three of the most abundant invertebrates (Hydrobia ulvae, Hediste diversicolor and Capitella capitata) showed significant increases in abundance in weed affected compared to weed-free plots. Gracilaria had less of an impact on macrobenthic assemblages leading to a more enriched community. Between-site differences in overall impact were related to their previous disturbance history.
\end{abstract}

(C) 2004 Elsevier B.V. All rights reserved.

Keywords: Eutrophication; Macroalgal blooms; Enteromorpha intestinalis; Gracilaria verrucosa; Macroinvertebrate assemblages

* Corresponding author. Tel.: +351-239-836-386; fax: +351-239-823-603.

E-mail address: gcardoso@ci.uc.pt (P.G. Cardoso). 


\section{Introduction}

Eutrophication of coastal waters as a result of anthropogenic activities is now widely recognized as a major, worldwide pollution threat (Vadas and Beal, 1987; Beukema, 1991; Fletcher, 1996; Norkko and Bonsdorff, 1996a,b; Beukema and Cadée, 1997; Valiela et al., 1997; Raffaelli et al., 1998; Lillebø et al., 1999; Pardal et al., 2000; Cloern, 2001; Sfriso et al., 2001; Cardoso et al., 2002). One of the direct symptoms of enrichment in estuaries is the extreme growth of opportunistic green macroalgae, often associated with increases in nutrition load (Raffaelli et al., 1989, 1998; Norkko and Bonsdorff, 1996a,b; Martins et al., 2001; Sfriso et al., 2001).

In intertidal areas, these algae can form dense mats, which negatively impact on the underlying macrofaunal assemblages, although at low biomasses there may be enhanced effects (Hull, 1987; Raffaelli et al., 1998). At low densities and for restricted periods of time, a patchy cover of algae increases habitat complexity and may facilitate local recruitment (Norkko and Bonsdorff, 1996a,b; Raffaelli et al., 1998). However, at high biomasses, macroalgal mats have been shown to negatively affect macrofaunal communities (Soulsby et al., 1982; Hull, 1987; Everett, 1994; Norkko and Bonsdorff, 1996a,b; Norkko et al., 2000). The majority of studies on the effects of macroalgal mats on intertidal macrofauna has focused only on green algae, mainly Enteromorpha (Raffaelli et al., 1998; Bolam et al., 2000) while few, if any, studies have concentrated on the effects of red macroalgal species.

In the Mondego estuary, Portugal, which has undergone significant eutrophication over the last two decades (Marques et al., 1997; Lillebø et al., 1999; Lopes et al., 2000; Pardal et al., 2000; Martins et al., 2001; Cardoso et al., 2002; Dolbeth et al., 2003), seasonal macroalgal blooms have been observed, particularly in the inner areas of the southern arm of the estuary from late winter to early summer when algae often collapse. These blooms are characterized by two quite different macroalgal taxa, the red Gracilaria verrucosa and the green Enteromorpha intestinalis, which have different morphological and ecological characteristics (Cabioc'h et al., 1992), and distinctly different macrofaunal responses might be expected (Raffaelli, 2000; Bolam and Fernandes, 2002). Here, we compare the effects of these two algae on the intertidal community in two different areas, an undisturbed sea grass bed and an eutrophic mudflat - to explore the effect of disturbance history on the outcome of such experiments.

\section{Materials and methods}

\subsection{Study site and experimental design}

The Mondego estuary is a warm temperate system located on the Atlantic coast of Portugal $\left(40^{\circ} 08 \mathrm{~N}, 8^{\circ} 50 \mathrm{~W}\right)$. It comprises two arms, northern and southern, separated by an alluvium-formed island (Murraceira Island) (Fig. 1). The northern arm is deeper (4-8 m during high tide, tidal range $1-3 \mathrm{~m})$ than the southern arm $(2-4 \mathrm{~m}$ during high tide, tidal range $1-3 \mathrm{~m}$ ) and is almost silted up in the upper zones, resulting in the freshwater outflow being mainly via the northern arm. Circulation in the southern arm is mostly 


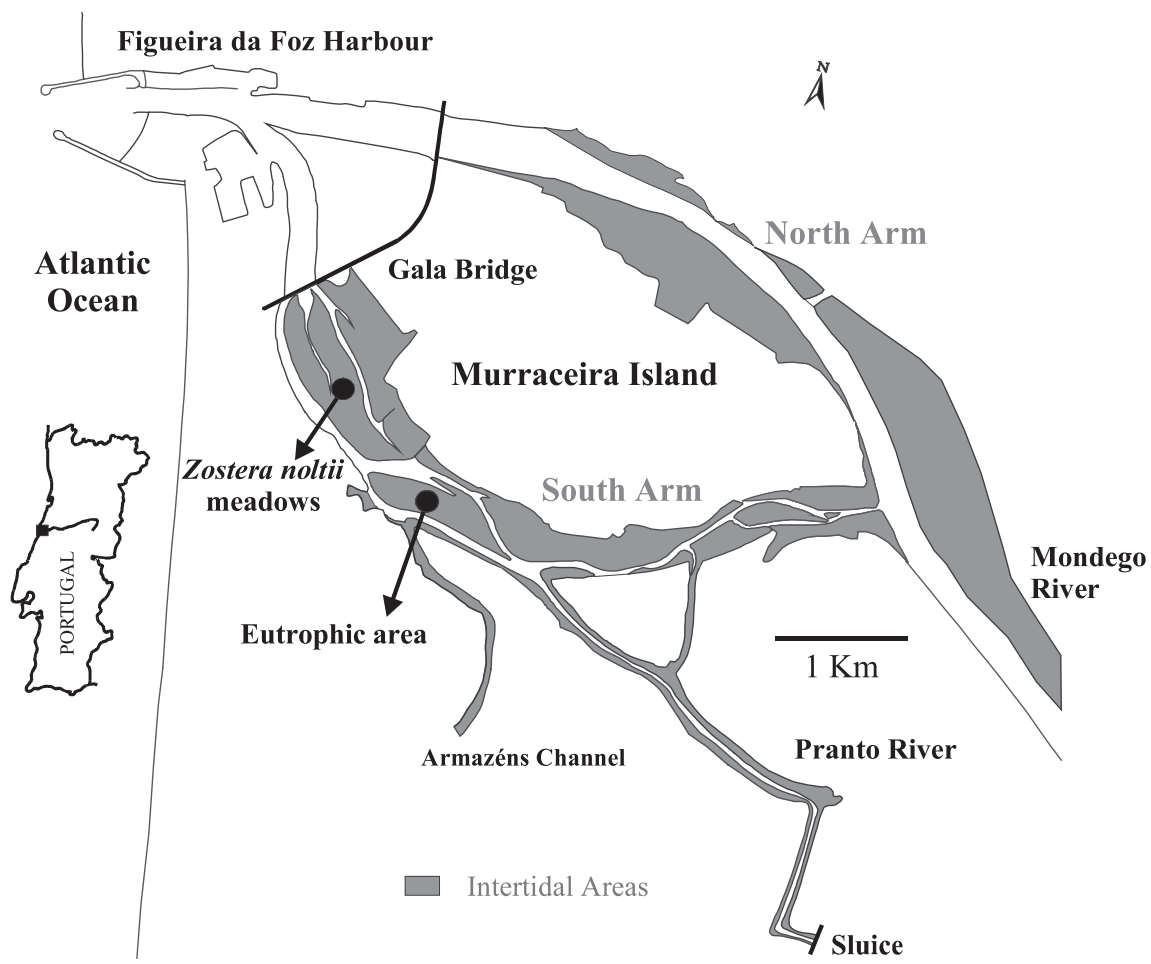

Fig. 1. Location of the Mondego estuary and experimental areas (Z. noltii meadows and eutrophic area).

dependent on the tides and on the freshwater input from the Pranto River, a small tributary. The discharge from this tributary is controlled by a sluice and is regulated according to the water needs of rice fields in the Mondego Valley (Flindt et al., 1997; Lillebø et al., 1999).

Two different areas were selected as experimental sites along a well-documented gradient (Marques et al., 1993a,b, 1997; Lillebø et al., 1999; Pardal et al., 2000; Martins et al., 2001; Cardoso et al., 2002; Dolbeth et al., 2003) in the southern arm of the Mondego estuary: (a) sea grass (Zostera noltii) meadows, corresponding to a non-eutrophic area, and (b) the eutrophic area upstream (Fig. 1). The Z. noltii meadows are located downstream and are characterized by a mud flat covered by sea grass and where the red macroalga ( $G$. verrucosa) is abundant, especially in late summer (50-100 $\mathrm{g} \mathrm{AFDW} \mathrm{m}^{-2}$ ) (Lillebø et al., 1999; Pardal et al., 2000). The eutrophic area is located upstream in the inner part of the estuary. This sandy-mud area is characterized by the absence of rooted macrophytes (for more than 15 years) but covered seasonally by green macroalgae, especially E. intestinalis (Pardal et al., 2000; Martins et al., 2001; Cardoso et al., 2002; Dolbeth et al., 2003). These two areas are characterized by different macrobenthic communities as a result of their distinct biological and physicochemical features (e.g. presence/absence of sea grasses, $\mathrm{pH}$, oxygen, salinity, total inorganic nitrogen) (Cardoso et al., 2002).

Within each of these experimental areas, six blocks, each consisting of eight treatment plots (plot size $=0.25 \times 0.25 \mathrm{~m}$ ), were set up in mid-September 2002 . For each of the two 
species of alga, three levels of algal biomass were added to the plots: $0.3 \mathrm{~kg}$ wet weight $\mathrm{m}^{-2}$ (low biomass), $1.0 \mathrm{~kg}$ wet weight $\mathrm{m}^{-2}$ (intermediate biomass) and $3.0 \mathrm{~kg}$ wet weight $\mathrm{m}^{-2}$ (high biomass). The biomasses used span the range found at the sites (see Fig. 2 and Cardoso et al., 2002) and are consistent with those used by other workers (Hull, 1987; Raffaelli, 1999, 2000; Raffaelli et al., 1998).

Algae were maintained in position under sheets of wire mesh anchored with corkscrewed wire at each corner, penetrating several centimetres into the sediment. Additionally, a weed control (treatment left clear of algae but covered with wire mesh) and a mesh control (treatment clear of both algae and mesh) were established within each block. A mesh control was used to reveal any artefacts associated with the mesh while the weed control was used to assess weed effects on invertebrate assemblages by comparing this treatment with the other algal treatments. Thus, each block contained a plot of low, intermediate and high algal biomass for the two algal taxa, a mesh control and a weed control. The blocks were dispersed over the site to provide a randomized block design.

Algal material used in the experiment was previously collected from sites on the estuary where the species occur naturally and washed carefully to remove any associated fauna.

The experiment was set up at low tide and ran for 4 weeks and redox potential assessed regularly. After 4 weeks, the redox potential under the algal treatments became markedly negative and the experiment was terminated. This experimental period is

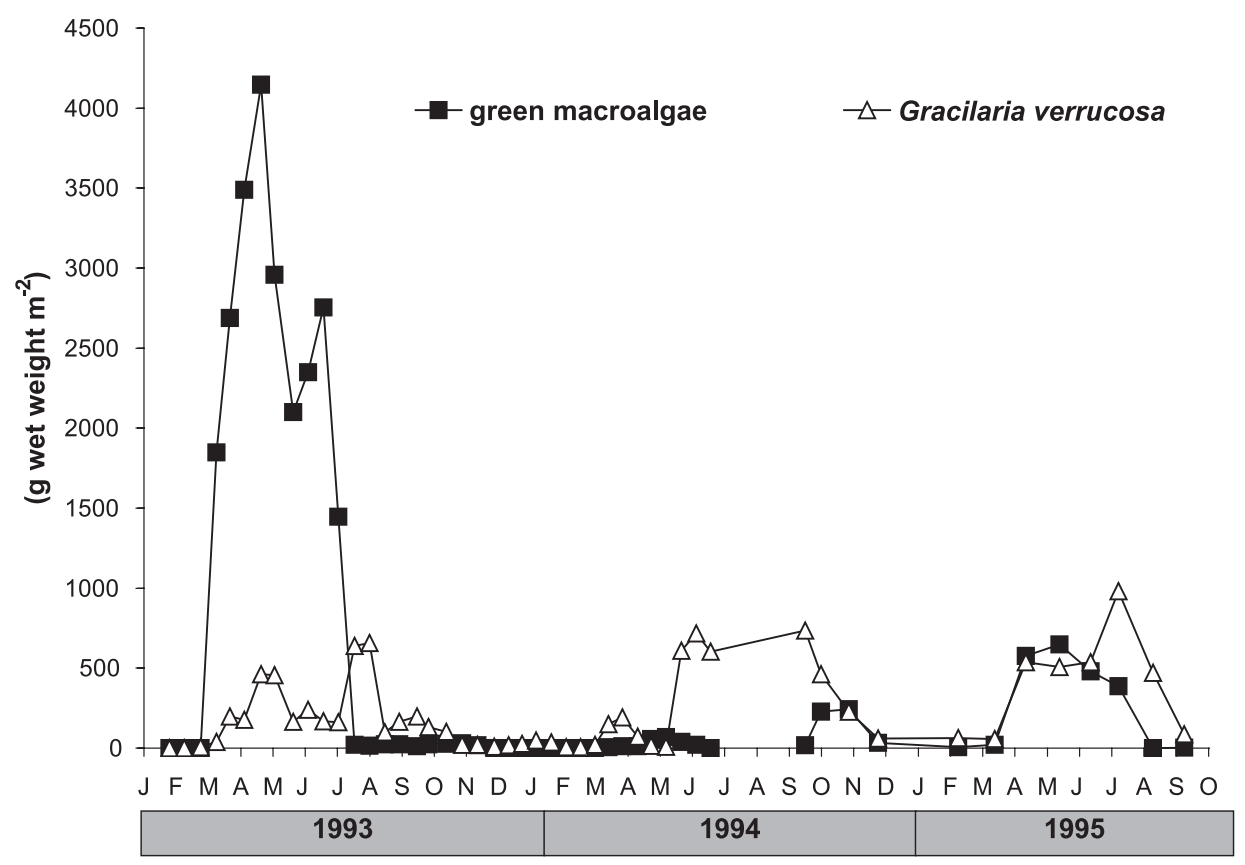

Fig. 2. Variation of algal biomass in the Mondego estuary from January 1993 to September 1995. 
somewhat shorter than that of other experiments (Hull, 1987; Raffaelli, 1999, 2000; Bolam and Fernandes, 2002), due to higher temperatures recorded at these sites, which led to a rapid algal decomposition and anoxia. For this reason, we decided to finish the experiment before an algal crash could happen. After this period, plots were sampled for macrofauna, taking a single core (containing material at the surface) from each plot using a 13-cm diameter corer to a depth of $10 \mathrm{~cm}$. Each sample was taken from the centre of the plot to avoid possible edge effects. Samples were washed in estuarine water over a $500 \mu \mathrm{m}$ mesh and the fauna retained preserved in $4 \%$ buffered formalin. Later, animals were separated and kept in $70 \%$ ethanol. Macrofauna was identified to the lowest possible taxon and counted. Sediment redox potential values were measured at the end of the experiment using an Eh electrode (Crison $\mathrm{pH} / \mathrm{mv}-506$ ). Recordings were made at $4-\mathrm{cm}$ depth.

\subsection{Data analysis}

Two-factor ANOVA (sites $\times$ algal treatments) was carried out followed by a multiple comparison test, the Tukey test, if significant, in order to determine where differences between treatments lay. All data were previously checked for normality using the Kolmogorov-Smirnov test and for homogeneity of variances using the Levene's test (Zar, 1996). Data not meeting these criteria were transformed appropriately (Zar, 1996) and checked again for normality and homocedasticity.

Between-treatment and between-site comparisons were also made at the community level using nonmetric Multi-Dimensional Scaling (MDS) ordination (Clarke and Warwick, 2001; Clarke and Gorley, 2001). The MDS plot was derived from the similarity matrix based species abundance data in each replicate plot for all the treatments. Raw counts were square root transformed to scale down the effects of very abundant species (Clarke and Warwick, 2001). To validate our interpretation of the MDS, we performed the ANOSIM test (analysis of similarities), built on a simple nonparametric permutation procedure, applied to the similarity matrix underlying the ordination of the samples (treatments) (Clarke and Warwick, 2001).

\section{Results}

\subsection{Macrofauna}

After 4 weeks of algal cover, there were effects of both algal species at both experimental sites. However, the effects were dependent on both the algal taxon and whether the site had a history of disturbance. The abundance of the several species suffered modifications, some of them increased while others decreased in the presence of weed (Enteromorpha and Gracilaria). Furthermore, there was no change in the total number of species: from the 18 species of the eutrophic area and 14 of the Z. noltii meadows, just 7 were sufficiently abundant for statistical analysis.

No significant effects of the mesh on species abundance were detected. For clarity, we review the effects of the two algal taxa at each site and then compare the sites. 


\subsubsection{Effects of algae in the disturbed area}

Overall, E. intestinalis had a greater impact than $G$. verrucosa for all biomass levels on most of the macroinvertebrate species, namely Cyathura carinata, Scrobicularia plana, Cerastoderma edule, Hediste diversicolor, Alkmaria romijni and Capitella capitata (Fig. 3 , Table 1). There were dose-dependent negative effects of both types of algae on $C$. carinata, while for the bivalves, $S$. plana and $C$. edule, there was a slight increase in numbers in the presence of low weed biomass then a marked decline at high weed biomass.

For the polychaete $H$. diversicolor, there was a general trend of an increase in abundance of this species with increasing weed biomass in the Enteromorpha plots.

A. romijni tended to slightly decline with increasing biomasses of Enteromorpha but there was no effect of Gracilaria.

C. capitata increased at high biomasses of Enteromorpha, but the response was the opposite for Gracilaria.
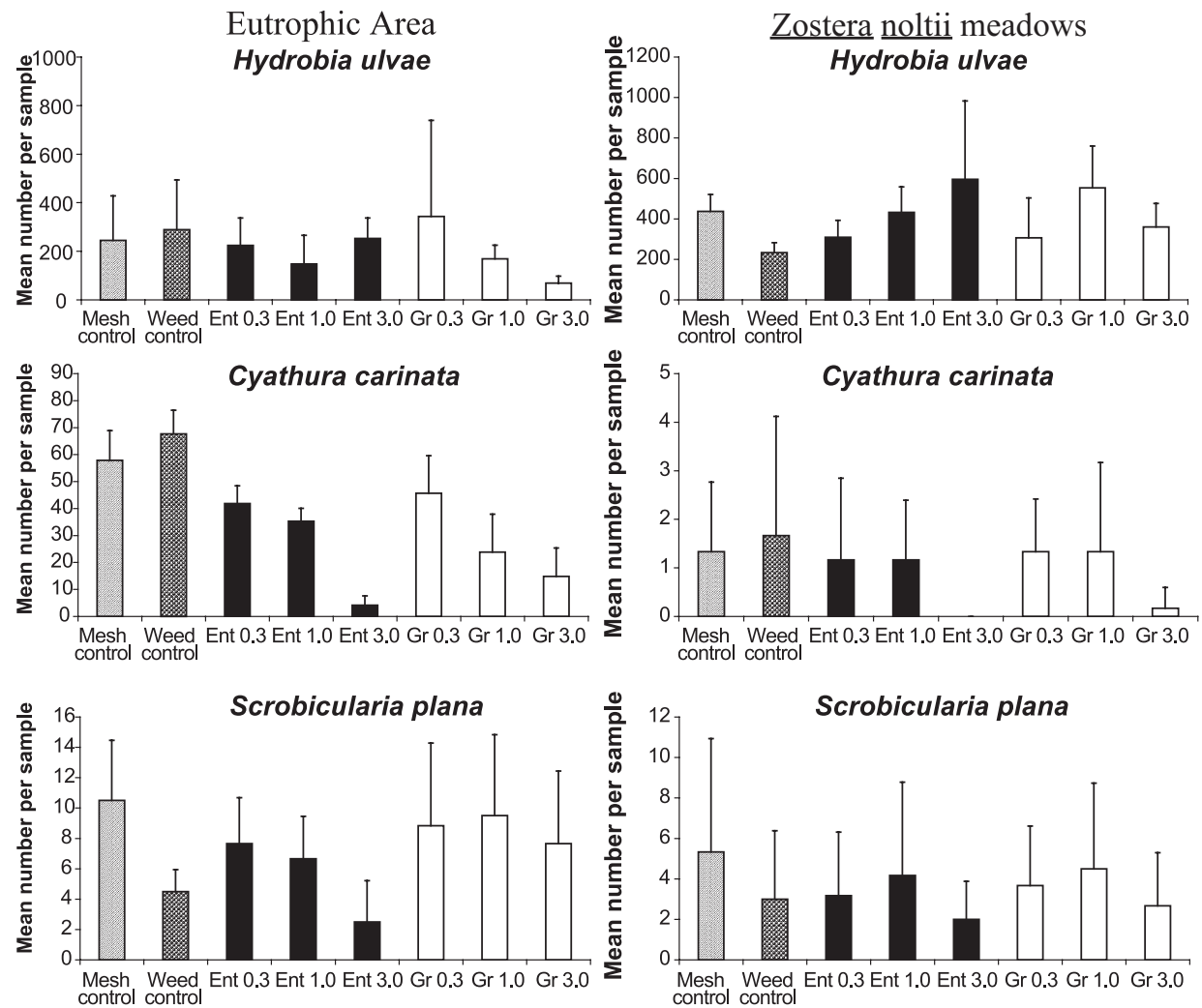

Fig. 3. Mean species abundance ( $+95 \%$ confidence intervals) after 4 weeks of experiment in the two experimental areas. 

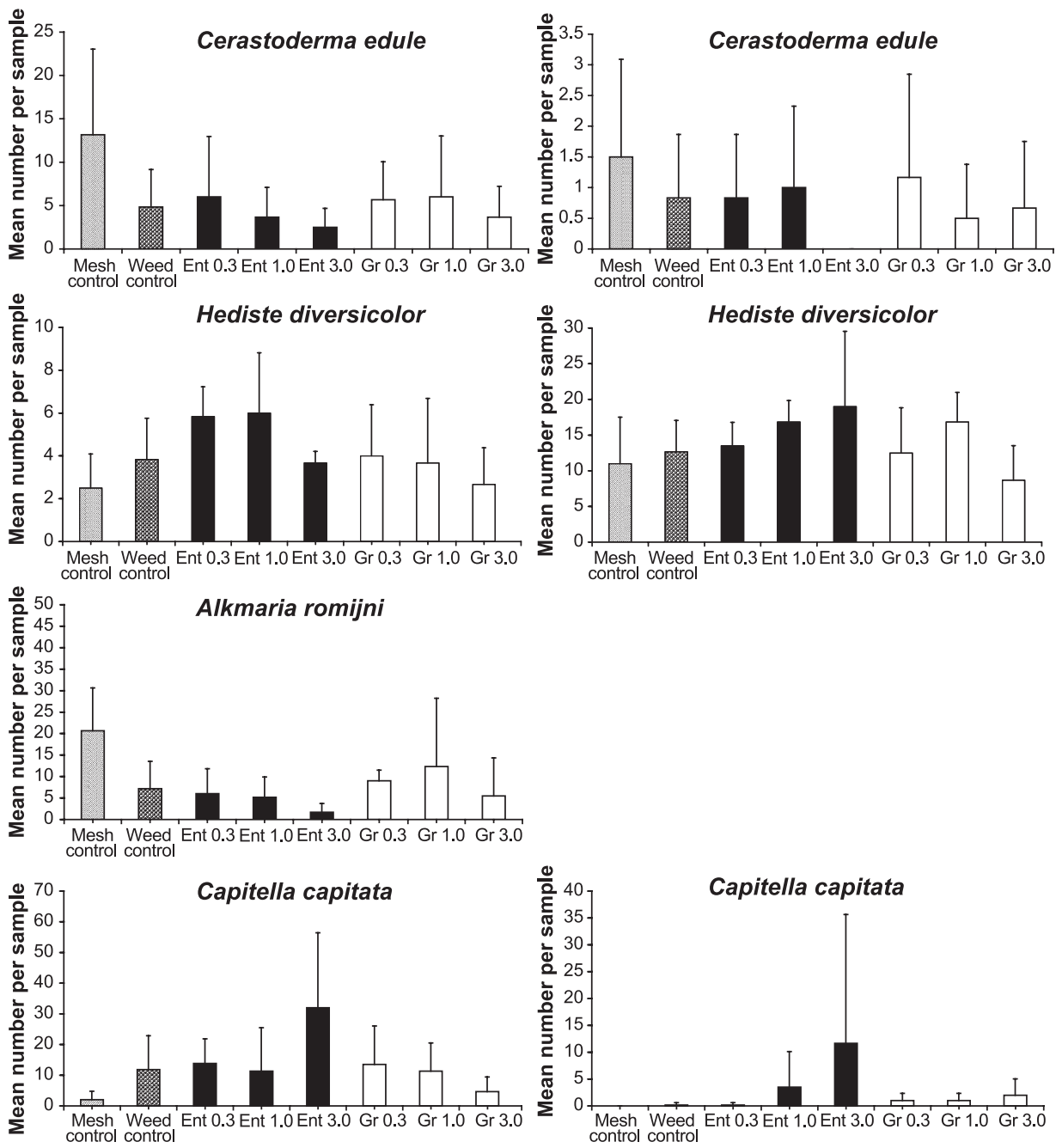

Fig. 3 (continued).

\subsubsection{Effects of algae in the sea grass meadows}

In contrast to the eutrophic area, the effects of green and red macroalgae on benthic macrofauna were considerably less in the sea grass meadows except for Hydrobia ulvae (Fig. 3) in the presence of Enteromorpha. As expected, H. ulvae exhibited a positive response to green macroalgae, showing an increase in abundance with increasing weed biomass. For most of the other species (e.g. C. carinata, C. edule, A. romijni) there were no effects possibly due to their low abundance in the cores. For the polychaete $H$. diversicolor there was slight tendency for an increase in density with increasing Enteromorpha biomass. 
Table 1

Statistical results of the two-way analysis of variance

\begin{tabular}{|c|c|c|c|c|}
\hline & \multicolumn{4}{|c|}{ Two-way ANOVA } \\
\hline & $\begin{array}{l}\text { Source of } \\
\text { variation }\end{array}$ & $\begin{array}{l}\text { Degrees of } \\
\text { freedom }\end{array}$ & $\begin{array}{l}\text { Significant } \\
\text { level }\end{array}$ & Tukey test \\
\hline \multirow[t]{3}{*}{ Hydrobia ulvae } & A & 1 & $* * *$ & - \\
\hline & $\mathrm{B}$ & 7 & ns & \\
\hline & $\mathrm{A} \times \mathrm{B}$ & 7 & $* *$ & \\
\hline \multirow[t]{3}{*}{ Cyathura carinata } & A & 1 & $* * *$ & - \\
\hline & $\mathrm{B}$ & 7 & $* * *$ & \\
\hline & $\mathrm{A} \times \mathrm{B}$ & 7 & $* * *$ & \\
\hline \multirow[t]{3}{*}{ Scrobicularia plana } & A & 1 & $* * *$ & E Ent $3.9<$ E Gr1.0 \\
\hline & $\mathrm{B}$ & 7 & $*$ & \\
\hline & $\mathrm{A} \times \mathrm{B}$ & 7 & ns & \\
\hline \multirow[t]{3}{*}{ Cerastoderma edule } & A & 1 & $* * *$ & - \\
\hline & $\mathrm{B}$ & 7 & $*$ & \\
\hline & $\mathrm{A} \times \mathrm{B}$ & 7 & ns & \\
\hline \multirow[t]{3}{*}{ Hediste diversicolor } & A & 1 & $* * *$ & $Z$ Ent $3.0>Z$ Gr3.0 \\
\hline & $\mathrm{B}$ & 7 & $* *$ & \\
\hline & $\mathrm{A} \times \mathrm{B}$ & 7 & ns & \\
\hline \multirow[t]{3}{*}{ Capitella capitata } & A & 1 & $* * *$ & - \\
\hline & $\mathrm{B}$ & 7 & $* * *$ & \\
\hline & $\mathrm{A} \times \mathrm{B}$ & 7 & ns & \\
\hline
\end{tabular}

Factor A-sites, factor $\mathrm{B}$ - algal treatments, $\mathrm{A} \times \mathrm{B}$-interaction, E-eutrophic area, $\mathrm{Z}-\mathrm{Z}$. noltii meadows, A. $* p<0.05$.

$* * p<0.01$.

$* * * p<0.001$.

\subsubsection{Two-way analysis of variance}

There were no significant algal treatment effects for $H$. ulvae $(P=0.347)$, but a difference between sites $(P=0.000)$ and a significant interaction $(P=0.003)$, almost certainly due to the different direction of the algal effects at the two sites (in the sea grass meadows, Hydrobia increases with algal biomass, while at the eutrophic area, abundance decreases).

C. carinata was significantly affected by site and algal treatments $(P=0.000$ for both factors) and there was a significant interaction $(P=0.000)$ term, probably because there were effects of algal treatments at the eutrophic area while in the sea grass meadows almost no effect was recorded.

For other species (e.g. S. plana, C. edule, H. diversicolor and C. capitata), there were both between-biomass and between-site differences but no interaction between the two factors (Table 1).

\subsubsection{Redox potential}

Sediment redox potential differed consistently between the two experimental areas (Fig. 4), being significantly lower in the eutrophic area consistent with the notion that this site is more disturbed than the sea grass bed. In the eutrophic area, redox potential became more negative with increasing algal biomass and weed treatment plots were significantly more reduced than the control plots (ANOVA, $F_{23}=3.10, P=0.029$ ). However, Tukey tests 


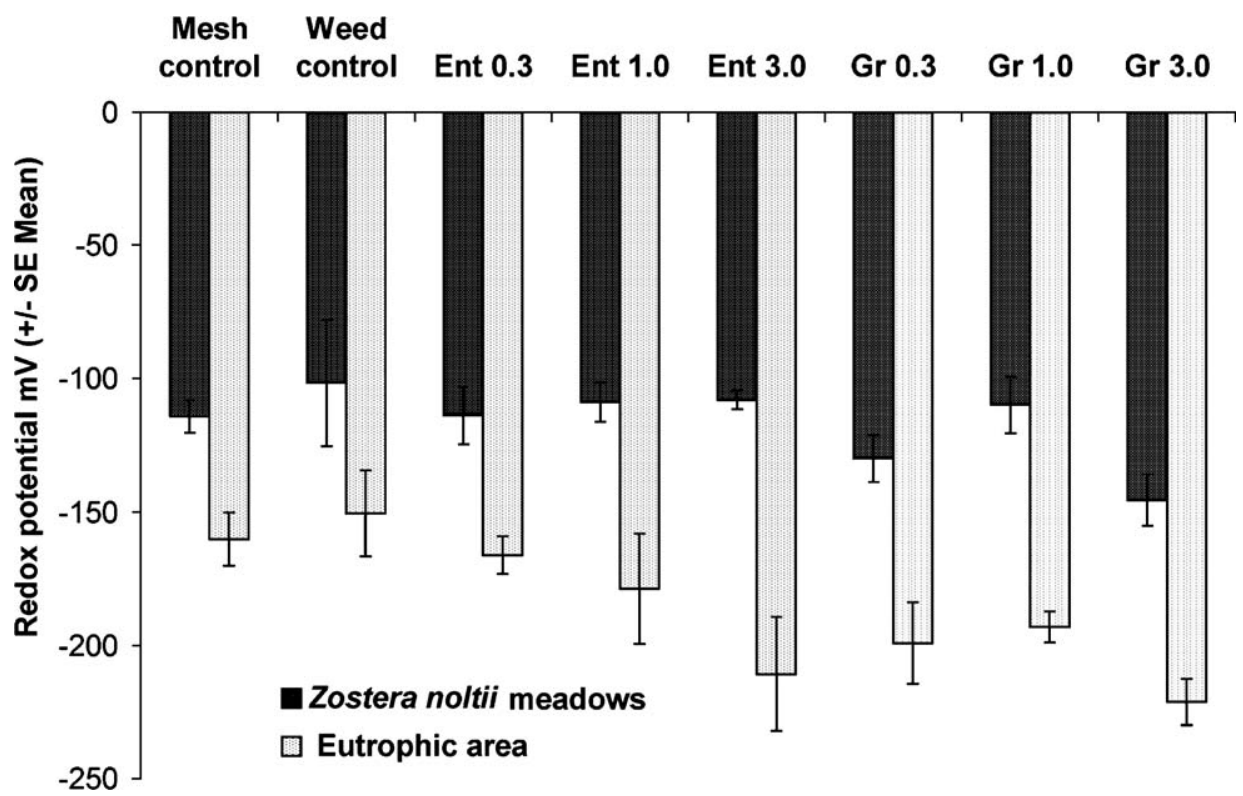

Fig. 4. Sediment redox potential measured at 4-cm depth at the Z. noltii meadows and eutrophic area.

failed to reveal any significant differences between the Enteromorpha and Gracilaria plots. In contrast, the sediments in the sea grass meadows did not show significant differences between the treatments.

\subsubsection{Multivariate analysis of the macrofaunal assemblages}

The macrobenthic communities of the two study areas are clearly separated in the MDS plot (Fig. 5). For the eutrophic area, macrobenthic assemblages within the weed controls are detached from the ones corresponding to the treatments with highest biomass of

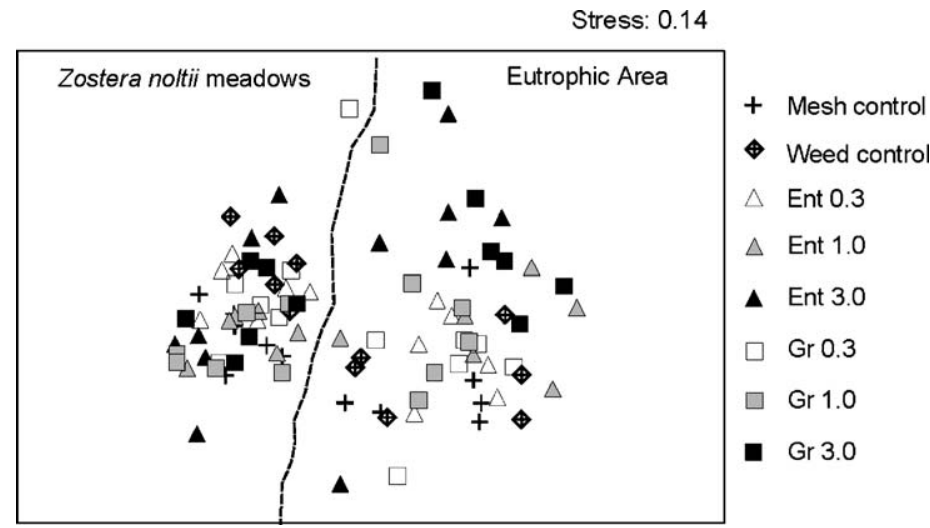

Fig. 5. Two-dimensional MDS ordination plot of macrobenthic communities. 
Table 2

Statistical results of the ANOSIM test applied to the MDS analysis

\begin{tabular}{|c|c|c|}
\hline Groups & $R$ statistic & Significant level \\
\hline$Z$ weed control $* Z$ Ent 1.0 & $R=0.439$ & $P=0.002$ \\
\hline$Z$ weed control $* Z$ Ent 3.0 & $R=0.444$ & $P=0.004$ \\
\hline $\mathrm{Z}$ weed control*Z Gr 1.0 & $R=0.506$ & $P=0.004$ \\
\hline Z Ent $0.3 * Z$ Ent 3.0 & $R=0.300$ & $P=0.022$ \\
\hline Z Ent $0.3^{*} \mathrm{Z}$ Gr 1.0 & $R=0.267$ & $P=0.039$ \\
\hline E weed control*E Ent 3.0 & $R=0.696$ & $P=0.002$ \\
\hline E weed control*E Gr 1.0 & $R=0.243$ & $P=0.019$ \\
\hline E weed control*E Gr 3.0 & $R=0.600$ & $P=0.002$ \\
\hline E Ent $0.3^{*}$ E Ent 3.0 & $R=0.515$ & $P=0.002$ \\
\hline E Ent $0.3 * \mathrm{E}$ Gr 1.0 & $R=0.269$ & $P=0.019$ \\
\hline E Ent $0.3 *$ E Gr 3.0 & $R=0.474$ & $P=0.002$ \\
\hline E Ent $1.0 *$ E Ent 3.0 & $R=0.476$ & $P=0.002$ \\
\hline E Ent $1.0 * \mathrm{E}$ Gr 1.0 & $R=0.196$ & $P=0.032$ \\
\hline E Ent $1.0 *$ E Gr 3.0 & $R=0.207$ & $P=0.039$ \\
\hline E Ent $3.0 * \mathrm{E}$ Gr 0.3 & $R=0.615$ & $P=0.002$ \\
\hline E Ent $3.0 * \mathrm{E}$ Gr 1.0 & $R=0.281$ & $P=0.015$ \\
\hline E Ent $3.0 *$ E Gr 3.0 & $R=0.344$ & $P=0.006$ \\
\hline E Gr $0.3 *$ E Gr 3.0 & $R=0.357$ & $P=0.002$ \\
\hline E Gr $1.0 *$ E Gr 3.0 & $R=0.241$ & $P=0.037$ \\
\hline
\end{tabular}

Enteromorpha and Gracilaria (Ent 3.0 and Gr 3.0), with the intermediate treatments occupying an intermediate position (Fig. 5). On the other hand, for the Zostera meadows, differences between treatments are less evident.

Significant differences were detected by ANOSIM between the two sites. Zostera meadows were significantly different from the eutrophic area at the $5 \%$ level $(R=0.786$; $P=0.001)$. ANOSIM test was also used to detect any differences between treatments in the two areas. The significant results are expressed in Table 2.

\section{Discussion}

The results of the present study demonstrate that the response of the macrobenthic species to macroalgae is different in the two study areas. Previous studies have indicated that the sediment environment in the two areas is quite different (Pardal et al., 2000; Cardoso et al., 2002) and this is confirmed by our redox results. These indicate that the sea grass meadows have a less hostile redox environment than the upstream disturbed area, which is probably less resistant to additional impacts. It is perhaps not surprising that the effects of the algae are more marked in the disturbed site (characterized by bare sediments).

Within each area, the responses of the benthic macrofauna to algal mats were algalspecies dependent, with some species being negatively affected and others being enhanced by the algae. On the other hand, for some species (e.g. A. romijni, H. ulvae) differences between the weed control and the mesh control were observed, however, no significant effects of the mesh on species abundance were recorded. 
For H. ulvae, one of the dominant taxa in the Mondego estuary (see Lillebø et al., 1999; Cardoso et al., 2002), there were positive effects of the green macroalgae in the Z. noltii meadows. This is consistent with other studies, which show that Hydrobia is an opportunistic species, utilising intertidal algal mats both as food resource and refuge (Soulsby et al., 1982; Norkko and Bonsdorff, 1996a,b; Norkko et al., 2000; Schanz et al., 2002). In contrast, the effects of this alga on Hydrobia, in the eutrophic area, were insignificant. This could be due to the short period of the experiment, which associated to the fragile population structure in this area (since during most of the time, only juveniles are present while adults only appear during periods with macroalgal blooms - see Cardoso et al., 2002) may not have allowed Hydrobia to respond in the same way as in the Z. noltii meadows. Gracilaria had no detectable effects on Hydrobia, probably because snails do not seem to use this type of algae as a food resource because of its stiff consistency, while its gross morphology possibly affords Hydrobia less protection than Enteromorpha.

The isopod C. carinata was negatively affected by both kinds of algae. The most likely explanation for this is the physical barrier created by mats of macroalgae that will interfere negatively with its feeding mechanism at the sediment-water interface (Cyathura is a deposit feeder and a predator). This response is similar to that observed for the amphipod Corophium volutator in other estuarine systems (Hull, 1987; Raffaelli, 1999, 2000). In the sea grass meadows, Cyathura is too rare to permit the detection of such effects.

For the bivalves, $S$. plana and $C$. edule, despite the low abundances found, there was a positive effect at low algal biomasses and a decline at high biomasses. This was much more evident within the Enteromorpha plots, possibly because Gracilaria does not create such a rigid barrier between infauna and the oxygenated water column and hence generate such a hostile sediment environment. The effects of Enteromorpha are similar to those in previous surveys carried out by Everett (1994), Bolam et al. (2000), Bolam and Fernandes (2002) and Lewis et al. (2003) but dissimilar to those reported by Hull (1987) and Raffaelli (1999). In the latter studies, the positive effects were due to the presence of a large number of juveniles, which was not the case here.

$H$. diversicolor, overall, seems to benefit from green algal cover since Enteromorpha, gives protection and constitutes a favourable food-source. Nevertheless for this endofaunal species, occurred a small decline in the eutrophic area at the highest biomasses, probably due to a new factor of stress induced by the large amount of weed that interferes with the sediment properties on an already disturbed area. This is consistent with the findings from other studies that tested lower weed biomasses (e.g. Norkko and Bonsdorff, 1996a). In contrast, $A$. romijni was negatively impacted by green macroalgae. This polychaete is a surface deposit feeder and the physical barrier created by macroalgae will probably interfere with its feeding behaviour.

Capitella is the only species that increased within the high biomass plots, although less so for Gracilaria. Capitella is an opportunistic detritivore species, usually associated with organically enriched sediments (Pearson and Rosenberg, 1978; Soulsby et al., 1982; Raffaelli, 1999, 2000; Bolam et al., 2000). Due to higher tissue thickness and lower surface/volume ratio, Gracilaria decomposition rate is much slower than the Enteromorpha one (sometimes only a few hours at temperatures above $25^{\circ} \mathrm{C}$ ), contributing less for food resources. Therefore, this species might be expected to do better in areas affected by green macroalgae than those covered by red macroalgae. 
The present study has shown that the morphological and ecological features of the algal species involved in blooms are an important determinant of algal-invertebrate interactions. The effects of Enteromorpha on the macrobenthic communities are much greater than those for Gracilaria in the present study. In the presence of Enteromorpha, the community tends to be impoverished, dominated mainly by small size opportunistic species, like $A$. romijni, $H$. ulvae and C. capitata, while in the presence of Gracilaria the negative effects are usually less (Marques et al., 2003; Cardoso et al., in press). In addition, the prior disturbance history of a site appears to be important in determining the extent of the impact of such blooms.

The present results and the one by Cardoso et al. (in press) confirmed the knowledge that, in the long term, sustained eutrophication together with spring macroalgal blooms may lead to complete replacement of sea grass habitat by unvegetated coarser sediments. The macrofaunal assemblages tend to be dominated by opportunistic invertebrate taxa with total macrobenthic biomass and species richness tending to decrease. Recovery from this situation may not only require reduction in nutrient loadings to the estuary, but also active sea grass restoration programmes to reverse the positive feedback processes involved in the decrease of the environmental quality of eutrophic systems.

\section{Acknowledgements}

This paper was supported by the FCT (Portuguese Foundation for Science and Technology) through a grant attributed to P.G. Cardoso (SFRH/BD/5350/2001). The authors are indebted to all colleagues from IMAR-Coimbra who assisted in the field and laboratory work. [RW]

\section{References}

Beukema, J.J., 1991. Changes in the composition of bottom fauna of a tidal area during a period of eutrophication. Mar. Biol. 111, 293-301.

Beukema, J.J., Cadée, G.C., 1997. Local differences in macrozoobenthic response to enhanced food supply caused by mild eutrophication in a Wadden Sea area: food is only locally a limiting factor. Limnol. Oceanogr. 42 (6), 1424-1435.

Bolam, S.G., Fernandes, T.F., 2002. The effects of macroalgal cover on the spatial distribution of macrobenthic invertebrates: the effect of macroalgal morphology. Hydrobiology 475/476, 437-448.

Bolam, S.G., Fernandes, T.F., Read, P., Raffaelli, D., 2000. Effects of macroalgal mats on intertidal sandflats: an experimental study. J. Exp. Mar. Biol. Ecol. 249, 123-137.

Cabioc'h, J., Floc'h, J.-Y., Le Toquin, A., Boudouresque, C., Meinesz, A., Verlaque, M., 1992. Guide des algues des mers d'europe. Delachaux et Niestlé S.A., Paris, 226 pp.

Cardoso, P.G., Lillebø, A.I., Pardal, M.A., Ferreira, S.M., Marques, J.C., 2002. The effect of different primary producers on Hydrobia ulvae population dynamics: a case study in a temperate intertidal estuary. J. Exp. Mar. Biol. Ecol. 277 (2), 173-195.

Cardoso, P.G., Pardal, M.A., Lillebø, A.I., Ferreira, S.M., Raffaelli, D., Marques, J.C., 2004. Dynamic changes in seagrass assemblages under eutrophication and implications for recovery. J. Exp. Mar. Biol. Ecol. 302, $233-248$.

Clarke, K.R., Gorley, R.N., 2001. Primer v5: User Manual/Tutorial. Primer-E, Plymouth.

Clarke, K.R., Warwick, R.M., 2001. Change in Marine Communities. An Approach to Statistical Analysis and Interpretation, 2nd edition. Primer-E, Plymouth. 
Cloern, J.E., 2001. Our evolving conceptual model of the coastal eutrophication problem. Mar. Ecol. Prog. Ser. $210,223-253$.

Dolbeth, M., Pardal, M.A., Lillebø, A.I., Azeiteiro, U.M., Marques, J.C., 2003. Short and long-term effects of eutrophication on the secondary production of an intertidal macrobenthic community. Mar. Biol. 143, $1229-1238$

Everett, R.A., 1994. Macroalgae in marine soft-sediment communities: effects on benthic faunal assemblages. J. Exp. Mar. Biol. Ecol. 175, 253-274.

Fletcher, R.L., 1996. The occurrence of "Green Tides"- - a review. In: Schramm, W., Nienhuis, P.H. (Eds.), Marine Benthic Vegetation. Recent Changes and the Effects of Eutrophication. Springer, Berlin, pp. 7-43.

Flindt, M.R., Kamp-Nielsen, L., Marques, J.C., Pardal, M.A., Bocci, M., Bendoricchio, G., Salomonsen, J., Nielsen, S.N., Jørgensen, S.E., 1997. Description of the three shallow estuaries: Mondego River (Portugal), Roskilde Fjord (Denmark) and the lagoon of Venice (Italy). Ecol. Model. 102, 17-31.

Hull, S.C., 1987. Macroalgal mats and species abundance: a field experiment. Estuar. Coast. Shelf Sci. 25, 519-532.

Lewis, L.J., Davenport, J., Kelly, T.C., 2003. Responses of benthic invertebrates and their avian predators to the experimental removal of macroalgal mats. J. Mar. Biol. Assoc. U.K. 83, 31-36.

Lillebø, A.I., Pardal, M.A., Marques, J.C., 1999. Population structure, dynamics and production of Hydrobia ulvae (Pennant) (Mollusca: Prosobranchia) along an eutrophication gradient in the Mondego estuary (Portugal). Acta Oecol. 20 (4), 289-304.

Lopes, R.J., Pardal, M.A., Marques, J.C., 2000. Impact of macroalgal blooms and wader predation on intertidal macroinvertebrates: experimental evidence from the Mondego estuary (Portugal). J. Exp. Mar. Biol. Ecol. $249,165-179$.

Marques, J.C., Rodrigues, L.B., Nogueira, A.J.A., 1993a. Intertidal macrobenthic communities structure in the Mondego estuary (Western Portugal): reference situation. Vie Milieu 43 (2-3), 177-187.

Marques, J.C., Maranhão, P., Pardal, M.A., 1993b. Human impact assessment on the subtidal macrobenthic community structure in the Mondego estuary (Western Portugal). Estuar. Coast. Shelf Sci. 37, $403-419$.

Marques, J.C., Pardal, M.A., Nielsen, S.N., Jørgensen, S.E., 1997. Analysis of the properties of energy and biodiversity along an estuarine gradient of eutrophication. Ecol. Model. 102, 155-167.

Marques, J.C., Nielsen, S.N., Pardal, M.A., Jørgensen, S.E., 2003. Impact of eutrophication and river management within a framework of ecosystem theories. Ecol. Model. 166, 147-168.

Martins, I., Pardal, M.A., Lillebø, A.I., Flindt, M.R., Marques, J.C., 2001. Hydrodynamics as a major factor controlling the occurrence of green macroalgal blooms in a eutrophic estuary: a case study on the influence of precipitation and river management. Estuar. Coast. Shelf Sci. 52, $165-177$.

Norkko, A., Bonsdorff, E., 1996a. Population responses of coastal zoobenthos to stress induced by drifting algal mats. Mar. Ecol. Prog. Ser. 140, 141-151.

Norkko, A., Bonsdorff, E., 1996b. Rapid zoobenthic community responses to accumulations of drifting algae. Mar. Ecol. Prog. Ser. 131, 143-157.

Norkko, J., Bonsdorff, E., Norkko, A., 2000. Drifting algal mats as an alternative habitat for benthic invertebrates: species-specific responses to a transient resource. J. Exp. Mar. Biol. Ecol. 248, 79-104.

Pardal, M.A., Marques, J.C., Metelo, I., Lillebø, A.I., Flindt, M.R., 2000. Impact of eutrophication on the life cycle, population dynamics and production of Ampithoe valida (Amphipoda) along an estuarine spatial gradient (Mondego estuary, Portugal). Mar. Ecol. Prog. Ser. 196, 207-219.

Pearson, T.H., Rosenberg, R., 1978. Macrobenthic succession in relation to organic enrichment and pollution of the marine environment. Oceanogr. Mar. Biol. Annu. Rev. 16, 229-311.

Raffaelli, D., 1999. Nutrient enrichment and trophic organisation in an estuarine food web. Acta Oecol. 20 (4), $449-461$.

Raffaelli, D., 2000. Interactions between macroalgal mats and invertebrates on the Ythan estuary, Aberdeenshire, Scotland. Helgol. Mar. Res. 54, 71-79.

Raffaelli, D., Hull, S., Milne, H., 1989. Long-term changes in nutrients, weed mats and shorebirds in an Estuarine System. Cah. Biol. Mar. 30, 259-270.

Raffaelli, D.G., Raven, J.A., Poole, L.J., 1998. Ecological impact of green macroalgal blooms. Oceanogr. Mar. Biol. 36, 97-125. 
Schanz, A., Polte, P., Asmus, H., 2002. Cascading effects of hydrodynamics on an epiphyte-grazer system in intertidal seagrass beds of the Wadden sea. Mar. Biol. 141, 287-297.

Sfriso, A., Birkemeyer, T., Ghetti, P.F., 2001. Benthic macrofauna changes in areas of Venice lagoon populated by seagrasses or seaweeds. Mar. Environ. Res. 52, 323-349.

Soulsby, P.G., Lowthion, D., Houston, M., 1982. Effects of macroalgal mats on the ecology of intertidal mudflats. Mar. Pollut. Bull. 13, 162-166.

Vadas, R.L., Beal, B., 1987. Green algal ropes: a novel estuarine phenomenon in the Gulf of Maine. Estuaries 10 (2), $171-176$.

Valiela, I., MaClelland, J., Hauxwell, J., Behr, P.J., Hersh, D., Foreman, K., 1997. Macroalgal blooms in shallow estuarios: controls and ecophysiological and ecosystem consequences. Limnol. Oceanog. 42 (5), 1105-1118. Zar, J., 1996. Biostatistical Analysis, 3rd ed. Prentice-Hall, Upper Saddle River, NJ. 